Manuscript submitted to International Journal of Cognitive Ergonomics

\title{
Rewritable Routines in Human Interaction with Public Technology
}

\author{
C. Baber \& N.A. Stanton $\dagger$
}

Industrial Ergonomics Group, School of Manufacturing \& Mechanical Engineering, University of Birmingham, B15 2TT $\dagger$ Department of Psychology University of Southampton, Highfield, Southampton.

SO17 1BJ 


\title{
Rewritable Routines in Human Interaction with Public Technology
}

\author{
C. BABER \& N.A. STANTON†
}

Industrial Ergonomics Group, School of Manufacturing \& Mechanical Engineering, University of Birmingham, Birmingham. B15 2TT

† Department of Psychology, University of Southampton, Highfield, Southampton SO17 1BJ

\section{Summary}

In this paper, the cognitive ergonomics of using public technology is investigated. A methodology for predicting human error with technology has been developed. Predictions from the method (combined with observation of user performance) form the foundation of the concept of 'rewritable routines'. This is in keeping with the tradition of building models of user cognition on the basis of observed and predicted errors. The concept is introduced and illustrated with examples. Implications for cognitive ergonomics are discussed. 


\subsection{Introduction}

A method for predicting user error in transactions with simple machines has been developed (Baber and Stanton, 1992; 1994; 1996; Stanton and Baber, 1996a, b). This method is called Task Analysis for Error Identification or TAFEI. The method combines a description of human activity (using hierarchical task analysis), with a description of human-machine interaction (using state-space diagrams). It is important to capture the interaction between human and machine at a state level in order to consider the types of errors which can arise as a consequence of the ensuing interaction. The approach has proved to have a reasonable level of validity, e.g., in a study comparing predicted errors using TAFEI with errors observed during actual use of a ticketvending machine, it was found that $100 \%$ of the predicted errors were observed and $80 \%$ of the observed errors had been predicted (Baber and Stanton, 1996). Further work, with novice users of the technique, has found that around $70 \%$ of the errors were predicted (Stanton and Baber, 1996c). Thus, while not a complete account of human error, it is proposed that the method has sufficient validity to be useful as a means of evaluating products; particularly as the method can be used prior to building functioning prototypes, e.g., by considering the paper-based designs of a product.

TAFEI is based on the assumption that human-machine interaction follows a sequence of states, and at each state, users will employ simple sequences of action to move them to the next state. Thus, planning of action will only be relevant for each state. This assumption is shared with Simon and Young (1988), who propose “...users engage only in simple forms of planning, [and] we can predict certain errors in user behaviour due to the characteristics of a particular interface design.” (p.591). Suchman (1987) has also noted that much of human-machine interaction (HMI) is situated in the immediate context of the transaction, with plans being developed on an ad hoc basis. It is not difficult to apply these assumptions to the description of HMI proposed by TAFEI. Thus, the first assumption in this paper will be that people develop 
plans which are relevant to each state in their interaction with a machine.

\subsection{Describing Human-Machine Interaction}

The approach taken in this paper can be contrasted with other models of human-computer interaction, such as GOMS (Card et al., 1983), TAG (Payne and Green, 1988) or TAKD (Diaper, 1989). It is argued that these models can be related to a particular stance on problem-solving. This stance is exemplified by the work of Newell and Simon (1972), which sees problem solving as the generation of procedures to move through a problem space. For instance, consider a GOMS analysis of using a ticket vending machine.

\section{USING A TICKET VENDING MACHINE}

Figure 1 shows a Hierarchical Task Analysis (HTA) diagram of using a ticket-vending machine on the London Underground railway network.

\section{[FIGURE 1 ABOUT HERE]}

A GOMS description of this task can be defined as follows (assuming the person is already in the ticket hall of a station):

GOAL: Obtain a valid ticket for travel from A to B from a ticket-vending machine GOAL: Find working machine

GOAL: check machine displays

GOAL: Specify ticket

GOAL: Enter fare type

GOAL: Enter journey type

GOAL: Enter destination

GOAL: Pay for ticket

GOAL: Collect ticket 
GOMS is based on an assumption that goals are held in a goal stack and can be 'pushed' on to the stack when there is space and 'popped' off the stack when complete. Placing the goals onto a stack allows the analyst to ask which Operator will be required to satisfy the goal (see table one). GOMS assumes that the procedure has been specified prior to action (although it can allow response to the interface). Typically, this means that the action will be known and the sequence of activity will involve working through a procedure, i.e., 'expert' performance.

$\begin{array}{llll}\text { Step } & \text { Contents of Goal Stack } & \text { Operator } & \text { Action } \\ 1 & \text { DO-CS } & & \\ 2 & \text { DO-CS, DO COMM-UT } & \\ 3 & \text { DO-CS, DO-COMM-UT, ACQ-UT } & & \\ 4 & \text { DO-CS, DO-COMM-UT, ACQ-UT } & \text { GET-NEXT-COMM } & \text { access memory } \\ 5 & \text { DO-CS, DO-COMM-UT, ACQ-UT } & & \\ 6 & \text { DO-CS, DO-COMM-UT } & & \\ 7 & \text { DO-CS, DO-COMM-UT, EXE-UT } & & \\ 8 & \text { DO-CS, DO-COMM-UT, EXE-UT, LOOK LOOK-FOR-MACHINE search area } \\ 9 & \text { DO-CS, DO-COMM-UT, EXE-UT, LOOK WORKING-MACHINE } & \text { read mode } \\ 10 & \text { DO-CS, DO-COMM-UT, EXE-UT, LOOK DECIDE } & \text { interpret mode } \\ 11 & \text { DO-CS, DO-COMM-UT, EXE-UT } & & \\ 12 & \text { DO-CS, DO COMM-UT } & \\ 13 & \text { DO-CS, DO-COMM-UT, ACQ-UT } & & \\ 14 & \text { DO-CS, DO-COMM-UT, ACQ-UT } & \text { GET-NEXT-COMM } & \text { access memory } \\ 15 & \text { DO-CS, DO-COMM-UT, ACQ-UT } & & \\ 16 & \text { DO-CS, DO-COMM-UT } & & \\ 17 & \text { DO-CS, DO-COMM-UT, EXE-UT } & & \text { access memory } \\ 18 & \text { DO-CS, DO-COMM-UT, EXE-UT, SPEC } & & \text { decide journey } \\ 19 & \text { DO-CS, DO-COMM-UT, EXE-UT, SPEC } & \text { SPECIFY TICKET } & \text { interpret option } \\ 20 & \text { DO-CS, DO-COMM-UT, EXE-UT, SPEC } & \text { DECIDE TYPE } & \text { access memory } \\ 21 & \text { DO-CS, DO-COMM-UT, EXE-UT, SPEC } & \text { READ SCREEN } & \text { decide fare type } \\ 22 & \text { DO-CS, DO-COMM-UT, EXE-UT, SPEC } & \text { SPECIFY FARE } & \\ 23 & \text { DO-CS, DO-COMM-UT, EXE-UT, SPEC } & \text { DECIDE FARE } & \\ 24 & \text { DO-CS, DO-COMM-UT, EXE-UT } & & \text { read screen } \\ 25 & \text { DO-CS, DO-COMM-UT, EXE-UT } & & \text { interpret key } \\ 26 & \text { DO-CS, DO-COMM-UT, EXE-UT, ENT } & & \text { hit a key } \\ 27 & \text { DO-CS, DO-COMM-UT, EXE-UT, ENT } & \text { SELECT KEY } & \\ 28 & \text { DO-CS, DO-COMM-UT, EXE-UT, ENT } & \text { DECIDE KEY } & \\ 29 & \text { DO-CS, DO-COMM-UT, EXE-UT, ENT } & \text { PRESS KEY } & \\ 30 & \text { DO-CS, DO-COMM-UT, EXE-UT } & & \\ & & & \\ & & & \\ & & \\ \end{array}$

Steps 12 to 30 will be repeated for the goals of defining journey type and destination 
Table One: GOMS Description of using a ticket vending machine

\section{PROBLEM SOLVING AND HUMAN-MACHINE INTERACTION}

The GOMS description shown in table one gives an idea of the complexity of decision making in the apparently trivial task of buying a ticket. Other studies have reported similar conclusions (Verhoef, 1988; Baber and Parker, 1994). In a string of transactions on a ticket vending machine,

performance is faster on the second and third trial than on the initial trial (Zwaga, 1988; Baber and Parker, 1994). These findings are also apparent in studies on automated-teller machine (ATM) use (Hatta and Iiyama, 1994). This suggests that, rather than 'expert' performance, i.e., having a procedure to recall from memory, people develop ad hoc routines for using public technology. Baber and Parker (1994) show that people make similar errors irrespective of level of experience, which suggests that the routines will be fragile and easily disrupted. This suggests that the routines will be influenced by the developing interaction between user and machine (an assumption which underlies TAFEI). On the other hand, patterns of automated-teller machine (ATM) use suggest that people tend to perform a limited range of transactions in their interaction with public technology (Burford and Baber, 1994). This could suggest that people will have well-rehearsed routines for these transactions. By way of illustration, consider the mundane task of inserting a card into an ATM; there are four orientations for the card and the orientations can differ across machines. Observations at ATM suggest that users insert card with little regard for printed instructions or labels on the machines. This implies a robust 'card insertion routine' for ATM use which is only handled when it fails. From the ticket-vending machine example, it would appear that there will be two types of routine used in interaction with public technology: one will result from ad hoc response to machine states; the other will result from simple, wellpractised routines. Neither of the routines will require the user to learn or remember a procedure 
for using the machine, or to have knowledge of how the machine works ${ }^{1}$.

The notion that problem solving involves movement through a defined problem space can be contrasted with that of Miller et al. (1960) who view problem solving as a continual adaptation of behaviour to a changing environment (in the test-operate-test-exit scheme). Other stances on problem solving see the use of feedback as paramount in influencing activity (Hayes-Roth and Hayes-Roth, 1979), or viewing planning as largely dependent on environmental cues (Suchman, 1987). Each stance can be criticised for the emphasis it places on the various components of problem solving, i.e., following a plan vs. adapting to changing cues.

TAFEI, like other HCI methods, is based on Newell and Simon's (1972) ideas of movement through a problem space. As people move through the problem space, so they change their knowledge of the problem; acquiring new information and rejecting old hypotheses. Newell and Simon (1972) propose that this problem solving behaviour requires the person to hold current knowledge in short-term memory and goals in long-term memory (which is also a feature of GOMS). Problem solving then involves processes to reduce the gap between current knowledge and goals. This is a form of the means-ends analysis approach to problem solving presented by Newell and Simon (1972). People tend to employ variations on means-ends analysis in problem solving, particularly when they lack expertise to develop more sophisticated strategies (Baron, 1994). Interaction with public technology is performed on an intermittent basis and people are unlikely to try to reach 'expert' level. Further, we assume that a goal can be reached via a number of relevant states, and the design of the machine could lead to states which appear relevant. In using public technology, the user will attempt to move from current state to the goal via relevant states. This is known in the problem solving literature as 'hill climbing'. Actions are selected by comparing the current state with the goal, and the action which is looks likely to lead to the goal will be chosen. This means that errors can arise when people reject 'correct' actions which do not look as if they will reach the goal, or can perform action which look as if they will reach the goal. 
The second assumption in this paper is that users of public technology cannot attend to all immediate information, and so some means of filtering is required. Also, we do not believe that complete goals are held in working memory, but that goals are decomposed into state-specific entities; problem solving then involves generating a routine which will satisfy the immediate goal. In order for this to work, we need to have some means of defining the relationship between current state and goal state. We term this relationship relevance.

\subsection{Relevance}

The use of public technology is goal-directed (Stanton and Baber, 1996). This means that there will be a specific end-state of the interaction, e.g., obtaining a valid ticket from a ticket vending machine, withdrawing cash from an automated-teller machine etc. Possession of a goal does not imply possession of plans to achieve that goal. However, the range of possible actions will be constrained by the design of the machine and the user's interpretation of the machine. TAFEI assumes that for each state in human-machine interaction, there will be a finite number of following states. The number of states will be limited by the design of the machine and the goals of the user. In this paper we introduce the notion, adapted from Hayes-Roth and Hayes-Roth (1979), of states from which a path to the goal can be seen. These states will be termed relevant states.

We assume that users will interpret the relevance of actions in terms of the relationship between the current state and the goal. This is known in the problem solving literature as 'back chaining', where people create subgoals which are achievable in the current state to allow progression to the goal (Larkin et al., 1980). This means that the user has to work forwards to the goal (to consider possible states) and backwards from the goal (to determine relevant states). As Duncan (1993) says, "Thus, the stimulus actually selected for control of behaviour is not simply the best match to a preexisting specification of what is needed in pursuit of a current goal. The goal itself may 
change; the selected stimulus is the one most relevant to the selected goal" (p.63). We assume that the user will seek relevant information during the interaction, where relevance is determined by goal definition, machine state and previous actions. The activity of seeking information is not intended to imply exhaustive search; rather the user will be defining the problem space at each state. Chi et al. (1981) demonstrate that problem classification can have a bearing on solution strategy and will vary between novice and expert. We assume that interaction with public technology involves a continuous process of problem classification.

METAPHORS AND MENTAL MODELS

Payne (1992) suggests that it is possible to place cognitive artefacts onto a taxonomy (see also Norman, 1991). In this way it is possible to discern similarities between items in the taxonomy. Figure 4 presents an initial scheme for ticket-vending machines and ATM, with the question being how do these differ? From the taxonomy, the ticket-vending machine and ATM differ along three dimensions: in terms of the order in which actions are performed, in terms of whether the machine is networked or not, and in terms of how items are selected.

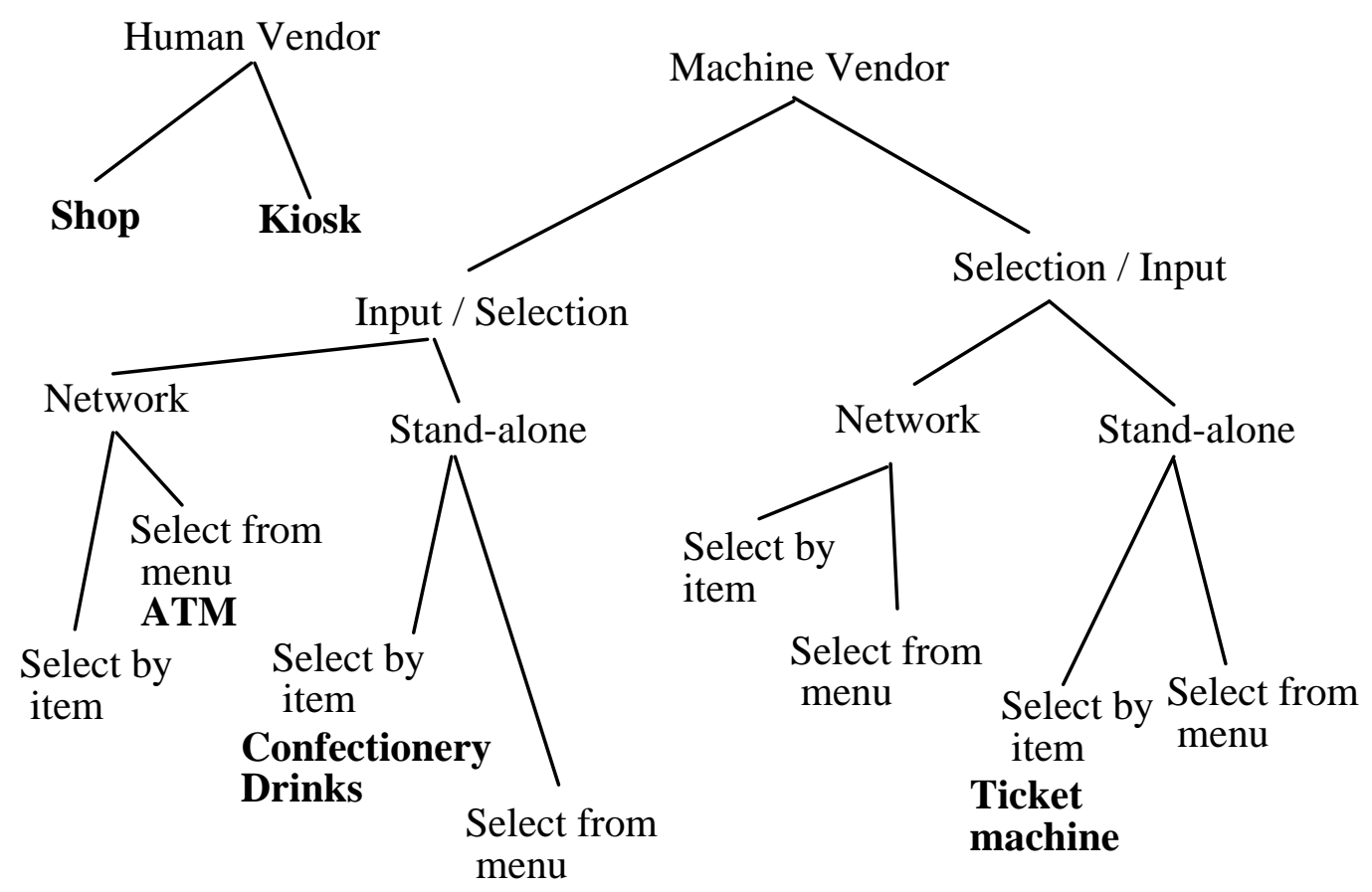


Figure two: Taxonomy of Vending Objects

These differences can be explained by the underlying design rationale of each artefact. For example, the design rationale of the ATM could be seen as ensuring security while presenting a range of services; the design rationale of the ticket-vending machine would be to mimic the ticket kiosk. We could suggest that an ATM would not be used as an analogy of the ticket-vending machine as they differ on so many dimensions. However, consider the ticket and confectionery vending machines: these share two of the three dimensions, and differ only on the sequence of actions. If we map the goals from the description of using a ticket vending machine on to figure two, common routines for ticket and confectionery vending machines can be seen.

For example, the one goal is to specify item, one is to pay for item and a third is to collect item. There might be common features for parts of the interaction which can maintain a routine across several artefacts. Consider using a ticket vending machine. There are two possible high-level routines which could be applied: (i.) in the 'Vending Machine' routine, the user inserts money and then makes a selection; (ii.) in the 'Ticket Clerk' routine, the user requests a tickets and then pays. Depending on which routine is used, the first action will be either to insert money or select a ticket. The routine which is likely to be used can be influenced by the design of the machine. Some of the errors, reported by Baber and Parker (1994), were due to people attempting to insert money before selecting a ticket. Thus, error could arise from a mismatch of appropriate routines. However, for the actions of using the machines (irrespective of sequence), performance will be similar.

\subsection{Rewritable Routines}

In order to move from current to relevant states, eliminating other possible states, the user needs to retain some record of the interaction and to have some means of assigning relevance to states. 
At each state, this record will be modified. Thus, it will need to be rewritable. We assume that the record will be held in working memory, presumably in the articulatory loop which has a limited duration (around 2 seconds). This means that unless the record is updated, it will decay. As the record will also guide the next action, we see this as a rewritable routine. To some extent this notion is similar to the 'partial provisional planning' hypothesis of Young and Simon (1987). Figure 2 presents a simple schematic of this process. The possible states (interpreted by the user from the machine) are compared against states which could lead to the goal. The comparator has a two-way connection to the the rewritable routines (with the routines both influencing the comparator, i.e., by defining relevance, and taking the output to define action).

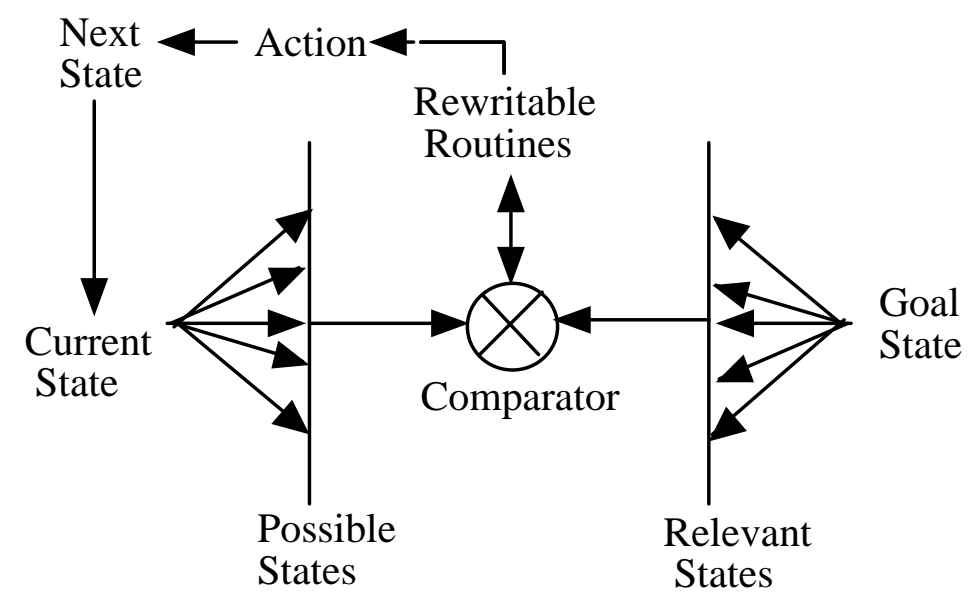

Figure three: Simple Schematic of Rewritable Routines

\section{MEMORY REQUIREMENTS}

It is proposed that the routines are held in working memory. This raises the question of how the routines are formed and what other memory is used. Bainbridge (1992) presents a description based on interdependencies in working storage, which is modified in figure 3. Typically, interaction with public technology will require this structure to be completely rebuilt, particularly 
when confronted with an entirely new design of machine. Further, even performance on wellknown machines may only impact on part of the description, e.g., repeated performance may lead to a reduction in the range of actions available, rather than changes in the prediction processes. If this is the case, the planning ahead or acting beyond the current state will be difficult; this might be one reason why so few people use the 'type ahead' facility in ATM.

If interaction with public technology has little need for prediction, then the process will involve step by step processing of states and planning at each state, i.e., situated activity (Suchman, 1988) or opportunistic planning (Norman, 1988). The argument is that interaction with public technology primarily involves defining available actions and comparing these with user goals. The notion of available action relates to the idea of an interface as a resource for action (Payne, 1990), in which the options presented to the user suggest what the user can do. This has been referred to as affordance by Norman (1988). Gaver $\left(19^{* *}\right)$ suggests that affordances can be sequential, e.g., a door handle affords gripping, a gripped handle affords turning, a turned handle releases a lock which releases the door which affords movement of the door etc.

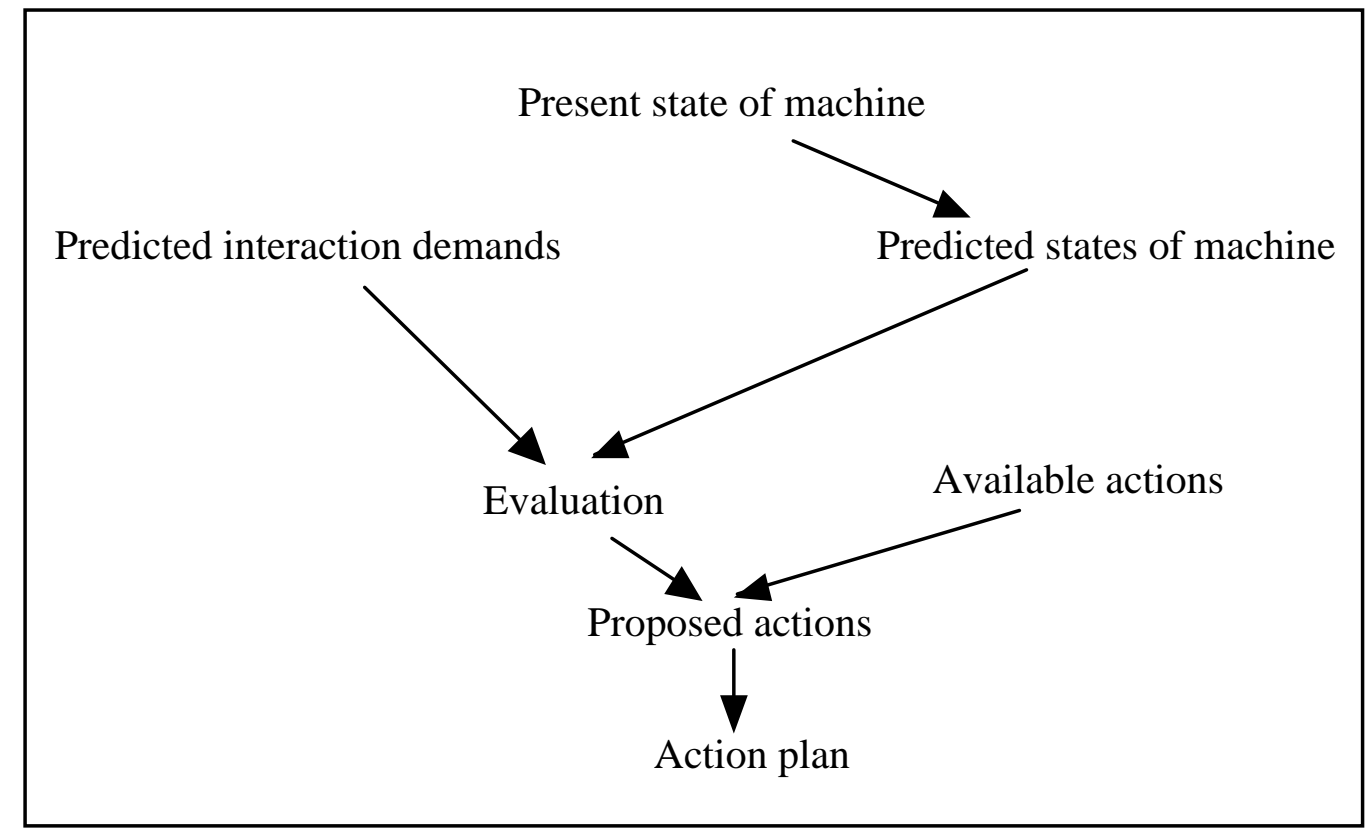


Figure 3: Interdependencies between working storage [from Bainbridge, 1991, p. 129]

The notion of available action will also relate to the idea of the user generating some local action specification, e.g., some belief that once action i has been performed it will be necessary to perform action $\mathrm{j}$ (if actions other than $\mathrm{j}$ are required, this will be confusing). This could be like the notion of adjacency pairs in linguistics (an adjacency pair is defined by commonly occurring pairs of linguistic act, such as 'question'-‘answer'). Are there adjacency pairs in human-machine interaction, i.e., local pairs of actions which always belong together. Returning to the door handle example, not only is there a sequence of affordances, but there is also a sequence of tasks: grip handle + turn, turn handle + (door / lock action) + move door. There appear to be several points in an interaction at which users 'know' an action has failed: users know an action has failed when nothing happens, i.e., when outcome feedback does not appear; users know an action has failed when there is no action feedback (touching a touchscreen and there is no 'beep'); users know an action has failed when they cannot perform the "adjacent" action. The "adjacent" action will be determined by knowledge of similar machines, feedback presented by the machine and user's interpretation of the feedback, i.e., its relevance.

\subsection{Running the Description}

\section{EXAMPLE ONE: USING A TICKET VENDING MACHINE}

Baber and Parker (1994) observed a number of errors which people make when using a ticket vending machine. Around $80 \%$ of these errors could be predicted by TAFEI (Baber and Stanton, 1996). The main errors were related to the mode of the machine, i.e., 'change given', 'exact money only', 'closed', 'waiting'. From the observations, people tended to use all machines as if they were in 'change given' mode. This suggests that state indication on the machine was sufficiently poor to allow confusion or that users were only employing some of the information. 
The machine studied had a display positioned around 1 metre above the machine to indicate mode, with a further display on a LED on the machine. From this we see that mode state is indicated. The fact that users missed these indications suggests that the comparator was operating on limited information, either because the users did not see the indicators or because the users took no notice of them. Not seeing the indicators would be a function of conspicuity (and this is certainly a possible explanation). Not notice the indicators would be a function of relevance; users would hold a definition of relevance in their rewritable routines which would not require the mode indication, e.g., the routine could prompt users to find an available machine (i.e., one with no queue); by definition, this could take users to machines which were in states other than 'change given' (there might be no queue at machines which are not 'working' or which are 'wait for assistance', and other users might have moved from 'exact money' when they realised the mode). The 'queue length' requirement, interestingly is not as apparent for ticket kiosks; people appeared to be content to join a queue of up to 6 people in preference to using the machines. There were errors observed in button use. This could be attributed to slips, with a large number of buttons in close proximity being likely to lead to the wrong button being pressed. While no data was collected on the buttons used, it seems unlikely that slips would account for all of these errors. A possible explanation lies in the fact that the button errors were often attributable to errors in sequence rather than operation. This suggests that users were working to a routine which differed from that anticipated by the machine.

TAFEI failed to predict some of the observed errors. These were 'lose place in interaction', 'lose ticket exit', 'confusion due to options not available'. It is proposed that each of these errors can be attributed to the description illustrated in figure 1. If the progression through states is not indicated, then the routine might not be updated appropriately. This would leave the user with a 'gap' in the routine. 'Lose ticket exit' referred to occasions when users were unable to locate the tray in which the ticket appeared. One explanation of this was that the ticket tray also served as the coin return tray; assuming that coin return and ticket dispensing were separate functions could 
lead to user seeking the ticket dispenser in another location. 'Confused by operations not available' relates current state to users interpretation of relevance, i.e., users could be seeking information which was either not present or was presented in another form.

*EXAMPLE TWO: USING A CONFECTIONERY VENDING MACHINE

\subsection{Discussion}

In this paper we have sought to demonstrate an initial specification for a theory of such humanmachine interaction. The theory contains three main concepts:

(i.) Human-machine interaction with public technology is state-dependent. This means that the amount of preparation and planning conducted prior to the transaction will be limited. Hence, there is little need to read the instructions on machines. Observations have suggested that people tend not to read the instructions, or if they do, only to read part of the instructions. We suggest that the user will seek information regarding action to perform in the initial state, but will not seek information relating to subsequent states until those states are reached.

(ii.) Human-machine interaction with public technology relies on rewritable routines. Users of public technology will plan actions which are relevant to the current state. When the next state is reached, the previous plans will be discarded. We believe that this is why even expert users of graphical-user interfaces are not able to recall the screen layout accurately (Mayes et al., 1988); not necessarily because the users rely solely on information in the world, as Mayes et al. (1988) 
suggest, but because the planning of activity is focussed on sequences of states. This would mean that users would recall only state relevant information (and not other details), and that users would primarily recall state exiting information (i.e., the details which take them from one screen to another). This issue is currently receiving attention in a series of studies.

(iii.) Human-machine interaction with public technology should be designed to support opportunistic planning. Users interpret information from the machine in terms of relevance, and relevance is state-dependent. This means that presenting information too early will either confuse users or will lead to the information being ignored (as in the ticket vending machine example).

\section{Notes}

1. From this discussion, it might be proposed that reducing the number of actions performed by users will improve performance. There have been a number of studies comparing multibutton systems with 'one button per task' interfaces (Felix et al., 1991; Verhoef, 1988; Wendel, 1990). The Wendel (1990) study indicates that 'one button per task' led to fewer entry errors than a numeric keypad, but also led to more irrelevant inputs; this latter finding was attributed to the fact that users were concentrating on the function keypad rather than on the feedback displayed. This work is supported by the finding of Verhoef (1988), who suggests that reduced button sets lead to users failing to read feedback or instructions presented to them. These studies suggest that planning of activity on public technology can be shaped by the level of feedback the users choose; in the case of reduced button sets, the feedback could simply be movement of the key which signals that the user can proceed to the next key in the sequence. If this is the case, then (i.) any feedback other than key movement need not be used; (ii.) the sequence needs to be specified by the user. From (ii.) it is possible that inappropriate sequences will be developed (perhaps as the result of keypad layout), and these sequences will not be corrected due to (i.). Felix et al. (1991) found step by step’ operation to be faster than free choice operation, possibly because the step by step procedure reduced planning requirements. 


\subsection{References}

Baber, C. and Parker, A. (1994) Buying a ticket on the Underground In Ed. S.A. Robertson Contemporary Ergonomics 1994 London: Taylor and Francis 46-51

Baber, C. and Stanton, N. A. (1992) Defining "problem spaces" in VCR use: the application of task analysis for error identification In Ed. E.J. Lovesey Contemporary

Ergonomics 1992 London: Taylor and Francis 418-423

Baber, C. and Stanton, N.A. (1994) Task analysis for error identification Ergonomics 37 (11) 1923-1942

Baber, C. and Stanton. N.A. (1996) Human error identification techniques applied to public technology: predictions compared with observed use Applied Ergonomics 27 119-131

Bainbridge, L. (1992) Mental models and cognitive skill: the example of industrial process operation In Ed.Y. Rogers, A. Rutherford and P.A. Bibby Models in the Mind London: Academic Press

Baron, J. (1994) Thinking and Deciding Cambridge: Cambridge University Press

Burford, B.C. and Baber, C. (1994) A user-centred evaluation of a simulated adaptive autoteller In Ed. S.A. Robertson Contemporary Ergonomics 1994 London: Taylor and Francis $\quad 64-69$

Card, S.K., Moran, T.P. and Newell, A. (1983) The Psychology of Human-Computer Interaction Hillsdale, NJ: LEA

Chi, M.T.H., Feltovich, P.J., and Glaser, R. (1981) Categorization and representation of physics knowledge by experts and novices Cognitive Science 5 121-152

Diaper, D. (1989) Task analysis for knowledge descriptions (TAKD): the method and an example In Ed. D. Diaper Task Analysis for Human-Computer Interaction Chichester: Ellis Horwood

Duncan, J. (1993) Selection of input and goal in the control of behaviour In Ed. A. Baddeley and L. Weiskrantz Attention, Selection, Awareness and Control Clarendon Press: Oxford 
Felix, D., Graf, W. and Krueger, H. (1991) User interfaces for public information systems In Ed. H.J. Bullinger Human Aspects of Computing I: design and use of interactive systems and work with terminals Amsterdam: Elsevier

Gaver, W. W. (1991) Technological Affordances. Proceedings of CHI'91 (New Orleans, Louisiana, April 28 - May 2, 1991) ACM: New York.

Hatta, K. and Iilyama, Y. (1994) Ergonomic study of automatic-teller machine operability International Journal of Human-Computer Interaction 3 295-309

Hayes-Roth, B. and Hayes-Roth, F. (1979) A cognitive model of planning Cognitive Science $3 \quad 275-310$

Larkin, J.H., McDermott, D., Simon, D.P. and Simon, H.A. (1980) Expert and naive performance in solving physics problems Science 208 1335-1342

Miller, G.A., Galanter, E. and Pribram, K.H. (1960) Plans and the Structure of Behaviour London: Holt, Rinehart and Winston

Newell, A. and Simon, H.A. (1972) Human Problem Solving Englewood Cliffs, NJ: Prentice Hall

Norman, D.A. (1988) The Psychology of Everyday Things New York: Basic Books Norman, D.A. (1991) Cognitive artefacts In Ed. J.M. Carroll Designing Interaction Cambridge: Cambridge University Press

Payne, S.J. (1991) A descriptive study of mental models Behaviour and Information Technology $10 \quad 3-21$

Payne, S.J. (1992) On mental models and cognitive artefacts In Ed.Y. Rogers, A. Rutherford and P.A. Bibby Models in the Mind London: Academic Press 103-118

Payne, S.J. and Green, T.R.G. (1986) Task action grammar: a model of the mental representation of task languages Human Computer Interaction 2 93-133

Simon, T. and Young, R.M. (1988) GOMS meets STRIPS: the integration of planning with skilled procedure execution in human-computer interaction In Ed. D.M. Jones and R. Winder People and Computer IV Cambridge: Cambridge University Press 581-594 
Stanton, N.A. and Baber, C. (1996a) A systems approach to human error identification Safety Science $22 \quad 215-228$

Stanton, N.A. and Baber, C. (1996b) Task analysis for error identification: applying HEI to product design and evaluation In Ed. P.W. Jordan, B. Thomas, B.A. Weerdmeester and I. McClelland Usability Evaluation in Industry London: Taylor and Francis 215-224

Stanton, N.A. and Baber, C. (1996c) Learning to predict errors: a case study of novice aquistion of TAFEI. Manuscript in preparation.

Suchman, L.A. (1987) Plans and Situated Actions Cambridge: Cambridge University Press

Verhoef, L.W.M. (1988) Decision making of users of a ticket vending machine Applied

Ergonomics $19 \quad 103-109$

Wendel, I.E.M. (1990) The human interface of a ticket vending machine In Ed. E.J. Lovesey Contemporary Ergonomics 1990 London: Taylor and Francis 334-339

Young, R.M. and Simon, T. (1987) Planning in the context of human-computer interaction In Ed. D. Diaper and R.Winder People and Computers III Cambridge: Cambridge University Press 